\title{
A Research on Cascaded H-Bridge Module Level Photovoltaic Inverter Based on a Switching Modulation Strategy
}

\author{
Wang Mao ${ }^{1} \mathbb{D}$, Xing Zhang ${ }^{1, *}$, Yuhua Hu ${ }^{1}$, Tao Zhao ${ }^{1}$, Fusheng Wang ${ }^{1}$, Fei Li ${ }^{1}$ and \\ Renxian Cao ${ }^{2}$ \\ 1 School of Electrical Engineering and Automation, Hefei University of Technology, Hefei 230009, China; \\ hfut_maow@163.com (W.M.); hfut_hyh@163.com (Y.H.); zt_kyyx@163.com (T.Z.); \\ wangfusheng@hfut.edu.cn (F.W.); lifei@hfut.edu.cn (F.L.) \\ 2 Sungrow Power Supply Co., Ltd., Hefei 230088, China; crx@sungrow.cn \\ * Correspondence: honglf@ustc.edu.cn; Tel.: +86-136-0560-1932
}

Received: 28 April 2019; Accepted: 13 May 2019; Published: 15 May 2019

check for updates

\begin{abstract}
The stable operating region of a photovoltaic (PV) cascaded H-bridge (CHB) grid-tied module level inverter is extended by adopting the hybrid modulation strategy. However, the traditional single hybrid modulation method is unable to regulate the DC-side voltage of each module precisely, which may aggravate the fluctuation of modules' DC-side voltages or even cause the deviation of modules' DC-side voltages under some fault conditions and, thus, degrade the energy harvesting of PV panels. To tackle this problem, a switching modulation strategy for PV CHB inverter is proposed in this paper. When the CHB inverter is operating in normal mode, the hybrid modulation strategy containing the zero state is adopted to suppress DC-side voltage fluctuation, thereby, improving the output power of PV modules. When the CHB inverter is operating in fault mode owing to failing solar panels, the hybrid modulation strategy without the zero state is utilized to make the DC-side voltages reach the references and, thus, maintain a higher energy yield under fault conditions. Experimental results achieved by a laboratory prototype of a single-phase eleven-level CHB inverter demonstrate both the feasibility and effectiveness of the proposed method.
\end{abstract}

Keywords: cascaded H-bridge; photovoltaic inverter; module level; switching modulation strategy; energy yield

\section{Introduction}

With the increasing demand for conversion efficiency during recent years, multilevel converter topologies have become more and more applied to the grid-connected PV generation system [1-4]. Among all kinds of multilevel inverters, the cascaded H-bridge (CHB) has many advantages, such as modularization, simplicity, and high reliability, which makes it become the most attractive topology [5-9]. In addition, the CHB topology makes it possible to, respectively, regulate each DC-side voltage and, thus, realizing the maximum power point tracking (MPPT) of each PV module. Therefore, the CHB inverter is considered to be one of the most suitable candidates for next generation PV inverters [10,11].

The energy loss caused by non-uniform solar radiation, degradation of PV modules and different types of partial shading is greatly decreased by module level MPPT. However, due to the unequal temperature and irradiance of PV modules, the output power of H-bridge unit varies greatly in the case of severe mismatching. This may lead to over-modulation of H-bridge units with high output power, thus, resulting in system instability and injection current distortion [12]. 
For the sake of expanding the stable operation range of the $\mathrm{CHB}$ inverter, some methods have been proposed. The power balance control strategy based on active component modification of duty cycles, and its effective power balance area are proposed in [13-15]. Although the system can operate stably by utilizing this method under slight mismatch conditions, there are still instability problems under severe mismatch conditions. In [16,17], a control strategy of reactive power compensation is proposed, which utilizes the power factor as the degree of freedom to stabilize the operation of the system. However, an increase in reactive power injection will lead to a decrease of the system power factor, which may be undesirable from the perspective of electric dispatchers. A new, improved MPPT method is presented in [18], which changes the working point of the over-modulated H-bridge unit to ensure that all $\mathrm{H}$-bridge units work in the stable operation region to improve the stability margins of the system. However, this will result in lower output power and make the system less-efficient. This is contrary to the original intention that all PV modules operate at a maximum power point to realize higher efficiency in energy harvesting.

Hopefully, In [19-21], the hybrid modulation strategy (HMS) is proposed, which utilizes a mixture of low-frequency PWM and high-frequency PWM methods to regulate the DC-side voltage and control the AC current separately. The HMS has been proved to maintain the stabilization of power rectifiers effectively even under critical operating conditions, because it provides higher DC-side utilization (the maximum modulation index of square wave can reach $4 / \pi$ ) compared with conventional sinusoidal pulse width modulation (SPWM). In [22,23], a control method of a grid-connected PV CHB inverter is proposed, which is based on the hybrid modulation strategy containing the zero state (HMSCZS). With HMSCZS, the system can operate stably under heavy mismatching conditions. Once the CHB inverter is operating in the fault mode, owing to failing solar panels, the HMSCZS fails to regulate the DC-side voltages to the references and may lead to low output power of the inverter. In [24], the hybrid modulation strategy without the zero state (HMSWZS) is proposed to maximize the range of stable operation of system. However, the HMSWZS cannot control the DC-side voltage of each module accurately. This may aggravate the fluctuation of modules' DC-side voltages, thus resulting in the decrease of the generated energy of PV modules.

Therefore, a switching hybrid modulation strategy (SHMS) is proposed in this paper. The HMSCZS is selected to suppress DC-side voltages fluctuation when the CHB inverter is operating in normal mode. Once the CHB inverter is operating in fault mode, owing to failing solar panels, the HMSWZS is utilized to control the DC-side voltages to track the references, thus maintaining a higher energy yield under fault condition. With this method, the average output power of the PV modules will be improved both in the normal and fault modes.

The paper is arranged as follows: In Section 2, the system configuration and control method are introduced. In Section 3, the existing problem of the HMSCZS and the HMSWZS is shown. In Section 4, the switching hybrid modulation strategy is put forward. In Sections 5 and 6 , the performance of the proposed strategy is verified by simulation and experimental results. Finally, in Section 7, a conclusion is drawn to summarize the paper.

\section{System Configuration}

The structure of the single-phase PV CHB module level grid-tied inverter is shown in Figure 1. The CHB module level inverter consists of $m \mathrm{H}$-bridge units. Each $\mathrm{H}$-bridge unit is connected to a PV module. $\mathrm{V}_{\mathrm{PV} i}$ and $\mathrm{I}_{\mathrm{PV} i}(I=1,2, \ldots, m)$ stand for the output voltage and current of PV module of $i$ th $\mathrm{H}$-bridge. $\mathrm{I}_{\mathrm{C} i}$ represents the current flowing through the capacitor on the DC-side of $i$ th H-bridge. $\mathrm{V}_{\mathrm{G}}$ stands for grid voltage. $\mathrm{I}_{\mathrm{S}}$ stands for grid current. $\mathrm{V}_{\mathrm{H} i}(I=1,2, \ldots, m)$ is the $i$ th $\mathrm{H}$-bridge output voltage and $\mathrm{V}_{\mathrm{HT}}$ is the total output voltage of $\mathrm{H}$-bridges. Figure 2 shows the configuration of the control diagram of $\mathrm{CHB}$ module level inverter. The voltage and current double closed-loop control are utilized to obtain the goal of the controlling. In order to decrease third harmonic component in the grid current, a digital $100 \mathrm{~Hz}$ notch filter is utilized to eliminate the second order harmonic in the total DC-side voltage $\mathrm{V}_{\mathrm{PV} 1}+\mathrm{V}_{\mathrm{PV} 2} \bullet \bullet \bullet+\mathrm{V}_{\mathrm{PV} m}$. The external voltage loop is in charge of controlling the 
filtered total DC-side voltages to the sum of the references $\mathrm{V}_{\mathrm{PV} 1}{ }^{*}+\mathrm{V}_{\mathrm{PV} 2}{ }^{*} \bullet \bullet \bullet+\mathrm{V}_{\mathrm{PV} m}{ }^{*}$ by a conventional PI controller. The internal current loop is responsible for controlling the grid current to a sinusoidal shape in phase with the grid voltage. In the paper, a direct-quadrature rotating frame control method for the single-phase inverter is used to achieve this goal because it can achieve zero steady-state error by utilizing a traditional PI regulator [25]. The output of the current loop regulator, $\mathrm{V}_{\mathrm{r}}$, serves as the modulation wave. In order to compensate for the harmonic component of the CHB inverter caused by the distorted grid voltage, the third, fifth, and seventh harmonic compensation algorithm is utilized [26,27].

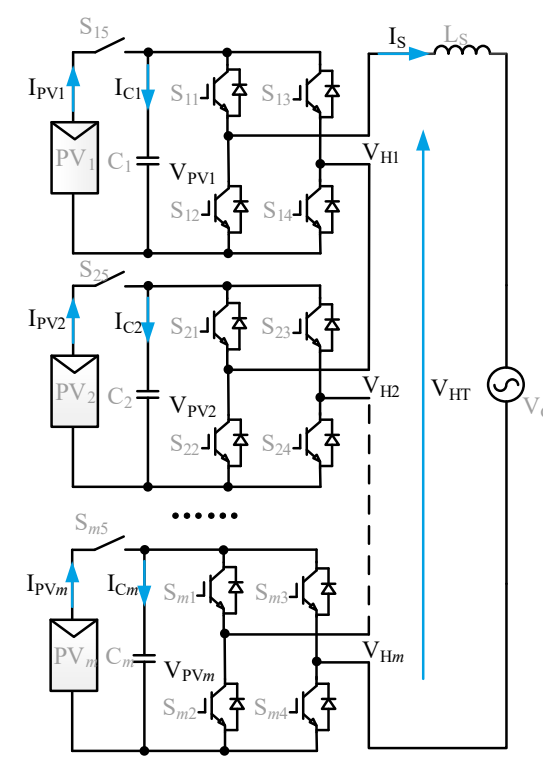

Figure 1. Structure of single-phase PV CHB module level inverter.

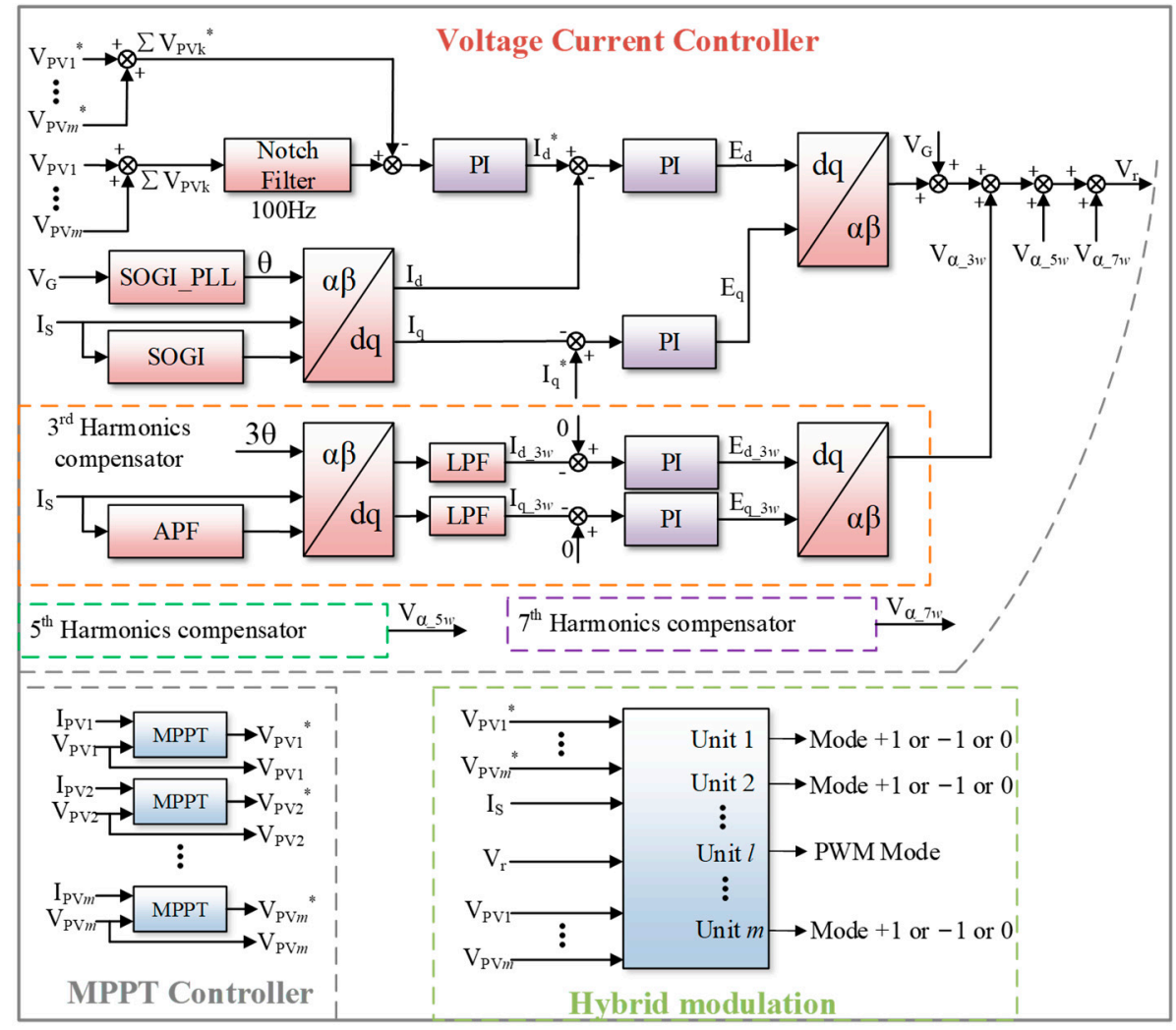

Figure 2. The control diagram of single-phase PV CHB module level grid-tied inverter. 
The balancing algorithm allocates suitable switching modes to each unit during every switching period based on the instantaneous value of modulation wave. For HMSCZS, only one unit operates in PWM state, the $\mathrm{K}-1(\mathrm{~K}=1,2, \ldots, m)$ units operate in the " +1 " or " -1 " state and other units work in the "0" state. However, for HMSWZS, only one unit operates in the PWM state, while the other units work in the " +1 " or " -1 " mode. Probable switching states of the $i$ th unit, $S_{i}$, and their corresponding output voltages are given in Table 1.

Table 1. Switch states of the ith unit.

\begin{tabular}{cc}
\hline Mode $\left(S_{i}\right)$ & Unit Output Voltage \\
\hline+1 & $+\mathrm{V}_{\mathrm{PV} i}$ \\
\hline-1 & $-\mathrm{V}_{\mathrm{PV} i}$ \\
\hline 0 & 0 \\
\hline $\mathrm{PWM}$ & PWM Reference \\
\hline
\end{tabular}

\section{Review of The Existing Hybrid Modulation Strategy}

\subsection{The Hybrid Modulation Strategy Containing the Zero State (HMSCZS)}

The HMSCZS proposed in $[19,23]$ maximizes the steady operation range of the system, because it provides higher DC-side utilization by adopting a square wave modulation. The major procedures of HMSCZS can be summarized as follows:

(1) Calculating the voltage error $\Delta \mathrm{V}_{\mathrm{PV} i}(I=1,2, \ldots, m)$ at the DC-side of each H-bridge unit:

$$
\Delta \mathrm{V}_{\mathrm{PV} i}=\mathrm{V}_{\mathrm{PV} i}-\mathrm{V}_{\mathrm{PV} i}^{*}
$$

(2) Sorting the voltage errors in ascending order $\left(\left[\Delta \mathrm{V}_{\mathrm{PV} 1}, \Delta \mathrm{V}_{\mathrm{PV} 2}, \ldots, \Delta \mathrm{V}_{\mathrm{PV} m}\right]\right)$ at a fixed frequency, $f_{\text {sort }}$.

(3) Mapping for the filtered DC-side voltages derived from the sorted vector of voltage errors $\left(\left[\mathrm{V}_{1}\right.\right.$, $\left.\mathrm{V}_{2}, \ldots, \mathrm{V}_{m}\right]$ ).

(4) Identifying the voltage area $l$ of $V_{\mathrm{r}}$ based on Equation (2):

$$
\sum_{i=1}^{l-1} \mathrm{~V}_{i}<\left|\mathrm{V}_{r}\right|<\sum_{i=1}^{l} \mathrm{~V}_{i}
$$

(5) Updating the H-bridge units' operating state. The $l-1(l=1,2, \ldots, m)$ units with the higher DC-side voltage are selected to be discharged in state " +1 " or " -1 " (according to the direction of grid-connected current), the $l$ th unit works in the PWM state, and the rest operate in state " 0 ".

As shown in Figure 3, the switching modes for an eleven-level CHB inverter with the HMSCZS method is presented. For instance, when $\sum_{i=1}^{3} \mathrm{~V}_{i}<\mathrm{V}_{\mathrm{r}}<\sum_{i=1}^{4} \mathrm{~V}_{i}$ and $\mathrm{I}_{\mathrm{S}}>0$, the switching modes of the

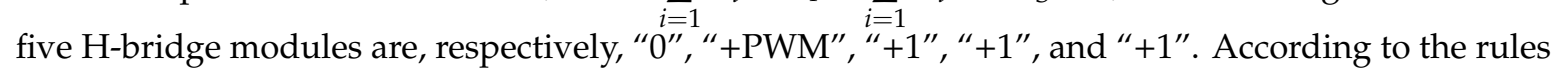
of HMSCZS, the switching mode of each H-bridge unit can only be " +1 ", " 0 ", or " $+\mathrm{PWM}^{\prime \prime}$ when $\mathrm{V}_{\mathrm{r}}$ is positive. Similarly, it can only be " -1 ", " 0 ", or " $-\mathrm{PWM"} \mathrm{when} \mathrm{V}_{\mathrm{r}}$ is negative. As shown in Figure 4, once the CHB inverter is operating in fault mode owing to failing PV modules, the fault H-bridge unit is always in the discharge state, whether the switching mode is " +1 ", " $+\mathrm{PWM}^{\prime}$, , -1 " or " $-\mathrm{PWM}$ ". The result is that the DC-side voltages of all H-bridge units diverge from the reference value and the generation of $\mathrm{CHB}$ inverter is low. 


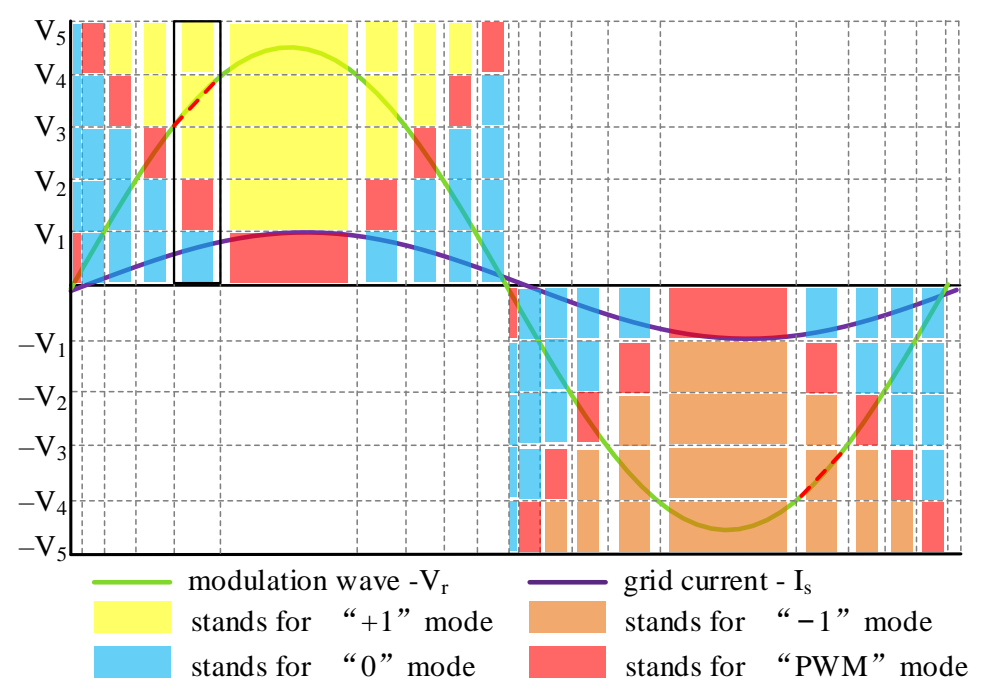

Figure 3. The switching modes for an eleven-level CHB inverter with the HMSCZS method.
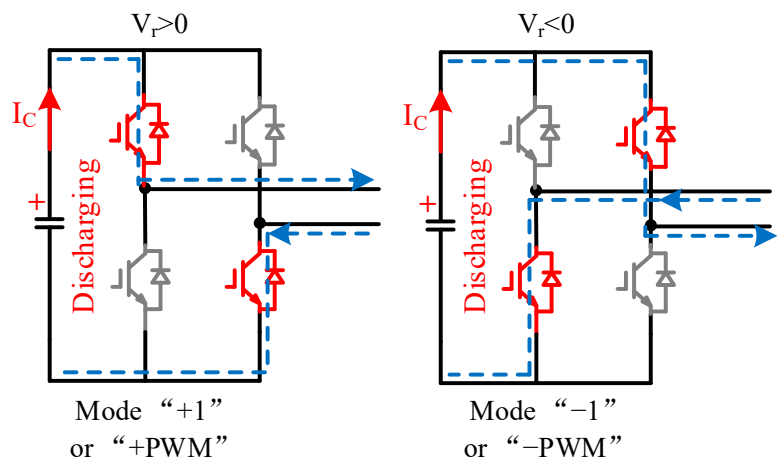

Figure 4. The switching modes of the fault H-bridge unit with the HMSCZS method.

\subsection{The Hybrid Modulation Strategy without the Zero State (HMSWZS)}

To overcome the shortcoming of the HMSCZS, the HMSWZS is presented in [21,24]. Different from the HMSCZS, in the HMSWZS the units with the lower voltage errors are selected to be charged in state " +1 " or " -1 " (according to the direction of grid-connected current) and no unit operates in the "0" mode. Figure 5 shows the switching modes for an eleven-level CHB inverter with the HMSWZS method. As depicted in the Figure 5, when $\sum_{i=1}^{1} \mathrm{~V}_{i}<\mathrm{V}_{\mathrm{r}}<\sum_{i=1}^{2} \mathrm{~V}_{i}$ and $\mathrm{I}_{\mathrm{S}}>0$, the switching modes of the five H-bridge modules are, respectively, " -1 ", " $-\mathrm{PWM}^{\prime \prime}$, " +1 ", “+1", and " +1 ". According to the rules of HMSWZS, as shown in Figure 6, the switching mode of the fault H-bridge unit can be " +1 ", " $+\mathrm{PWM}$ ", " -1 ", or "-PWM" regardless of the polarity of $\mathrm{V}_{\mathrm{r}}$. Therefore, compared with the HMSCZS, the HMSWZS is able to maintain the DC-side voltages balance and a higher energy yield under fault condition.

However, as is illustrated in [23], the HMSWZS may aggravate the DC-side voltages fluctuation of H-bridge units and, thus, lead to losses in energy harvesting of PV modules. As shown in Equation (3), $\Delta \mathrm{U}_{c i}(\mathrm{i}=1,2, \ldots, m)$, the fluctuation of the DC-side voltage of the $i$ th H-bridge unit during a sorting cycle is composed of two parts: $\Delta \mathrm{U}_{c i 1}$ and $\Delta \mathrm{U}_{c i 2}$. Based on the superposition theorem of linear circuits, the fluctuation of the DC-side voltage could be regarded as the sum of fluctuations produced by two separate parts:

$$
\begin{aligned}
\Delta \mathrm{U}_{\mathrm{c} i} & =\frac{1}{\mathrm{C}_{i}} \int_{0}^{\frac{1}{f_{\text {sort }}}}\left(\mathrm{I}_{\mathrm{PV} i}-\mathrm{S}_{i} \mathrm{I}_{\mathrm{S}}\right) d t \\
& =\frac{\mathrm{I}_{\mathrm{PV} i}}{\mathrm{C}_{i} f_{\text {sort }}}-\frac{1}{\mathrm{C}_{i}} \int_{0}^{\frac{1}{f_{\text {sort }}}} \mathrm{S}_{i} \mathrm{I}_{\mathrm{s}} d t \\
& =\Delta \mathrm{U}_{\mathrm{c} i 1}+\Delta \mathrm{U}_{\mathrm{c} 2}
\end{aligned}
$$


where:

$$
\begin{gathered}
\Delta \mathrm{U}_{\mathrm{c} i 1}=\frac{\mathrm{I}_{\mathrm{PV} i}}{\mathrm{C}_{i} f_{\text {sort }}} \\
\Delta \mathrm{U}_{\mathrm{c} i 2}=-\frac{1}{\mathrm{C}_{i}} \int_{0}^{\frac{1}{f_{\text {sort }}}} \mathrm{S}_{i} \mathrm{I}_{\mathrm{s}} d t
\end{gathered}
$$

If the HMSWZS is utilized, $\Delta \mathrm{U}_{\mathrm{c} i}$ has two possible values: $\Delta \mathrm{U}_{1 \min }$ and $\Delta \mathrm{U}_{1 \max }$ (if the polarity of $\mathrm{S}_{i}$ and $\mathrm{I}_{\mathrm{s}}$ is the same, $\Delta \mathrm{U}_{\mathrm{c} i}=\Delta \mathrm{U}_{1 \min }$, otherwise, $\left.\Delta \mathrm{U}_{\mathrm{c} i}=\Delta \mathrm{U}_{1 \max }\right)$, where:

$$
\begin{aligned}
\Delta \mathrm{U}_{1 \min } & =\Delta \mathrm{U}_{\mathrm{c} i 1}-\left|\Delta \mathrm{U}_{\mathrm{ci} 2}\right| \\
\Delta \mathrm{U}_{1 \mathrm{max}} & =\Delta \mathrm{U}_{\mathrm{c} i 1}+\left|\Delta \mathrm{U}_{\mathrm{c} i 2}\right|
\end{aligned}
$$

If the HMSCZS is employed, $\Delta \mathrm{U}_{c i}$ also has two possible values: $\Delta \mathrm{U}_{2 \min }$ and $\Delta \mathrm{U}_{2 \max }$ (if the value of $\mathrm{S}_{i}$ is not equal to zero, $\Delta \mathrm{U}_{c i}=\Delta \mathrm{U}_{2 \min }$, otherwise, $\Delta \mathrm{U}_{c i}=\Delta \mathrm{U}_{2 \max }$ ), where:

$$
\begin{gathered}
\Delta \mathrm{U}_{2 \min }=\Delta \mathrm{U}_{\mathrm{c} i 1}-\left|\Delta \mathrm{U}_{\mathrm{c} i 2}\right| \\
\Delta \mathrm{U}_{2 \max }=\Delta \mathrm{U}_{\mathrm{c} i 1}
\end{gathered}
$$

It is obvious that $\Delta \mathrm{U}_{1 \min }$ is equal to $\Delta \mathrm{U}_{2 \min }$ and $\Delta \mathrm{U}_{1 \max }$ is greater than $\Delta \mathrm{U}_{2 \max }$. Compared with the HMSCZS, the HMSWZS may lead to larger fluctuation of DC-side voltages of H-bridge units and thus more energy will be lost.

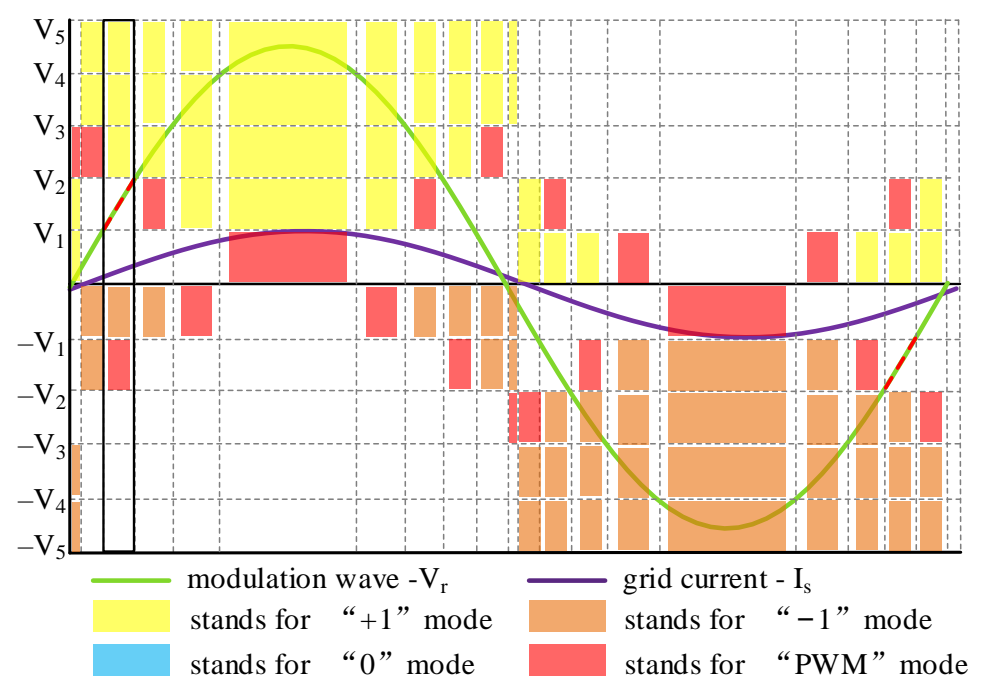

Figure 5. The switching modes for an eleven-level CHB inverter with the HMSWZS method.
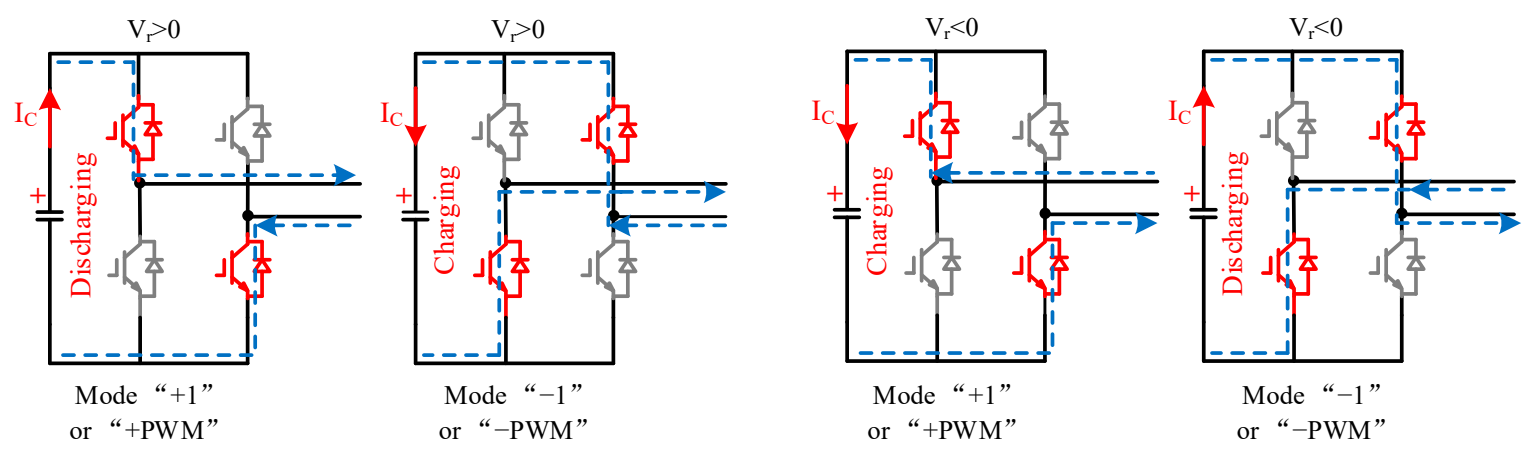

Figure 6. The switching modes of the fault H-bridge unit with the HMSWZS method. 


\section{The Switching Hybrid Modulation Strategy}

A switching hybrid modulation strategy (SHMS) based on the HMSCZS and HMSWZS is proposed to maximize the output power of PV panels. When the CHB inverter is operating in the normal mode, the HMSCZS is adopted to suppress DC-side voltages fluctuation and, thus, realizing higher efficiency in energy harvesting. When the $\mathrm{CHB}$ inverter is operating in the fault mode owing to failing solar panels, the HMSWZS is utilized to control the DC-side voltages to reach the references, thus, maintaining a higher energy yield under the fault condition. Figure 7 shows the major procedures of the SHMS, which are basically the same as HMSCZS.

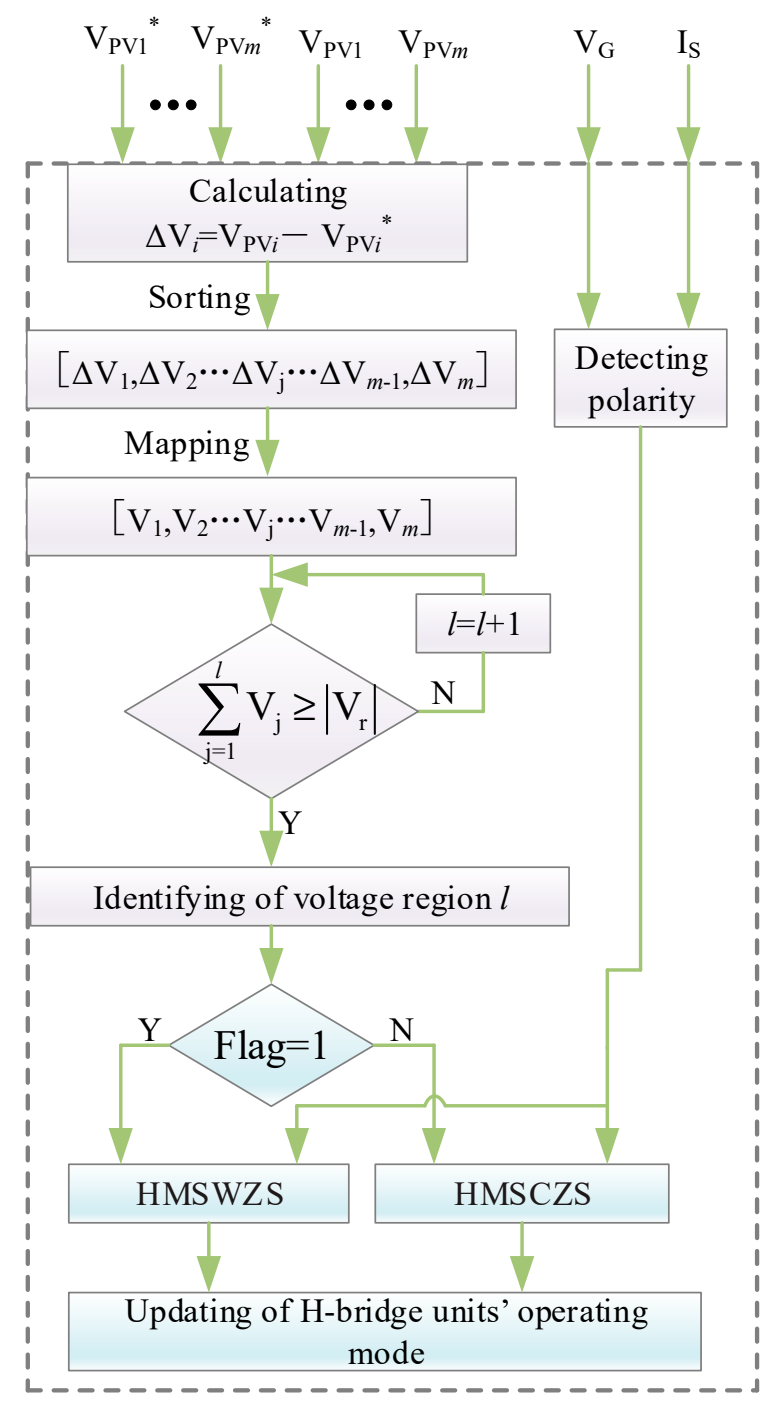

Figure 7. Flowchart of the proposed switching hybrid modulation strategy.

In consideration of the direction of $I_{S}$ and $V_{r}$, and assuming that the modulation wave $V_{r}$ is in area $l$, the SHMS method allocates suitable switching modes to each H-bridge unit based on the following rules:

\subsection{Normal Mode}

(1) When $\left(\mathrm{V}_{\mathrm{r}}>0\right.$ and $\left.\mathrm{I}_{\mathrm{S}}>0\right),(l-1)$ units with higher voltage errors are discharging in the " +1 " state, $(m-l)$ units with lower voltage errors operate in the " 0 " state, and the $l$ th unit works in PWM state. 
(2) When $\left(\mathrm{V}_{\mathrm{r}}>0\right.$ and $\left.\mathrm{I}_{\mathrm{S}} \leq 0\right),(l-1)$ units with lower voltage errors are charging in the " +1 " state, $(m-l)$ units with higher voltage errors operate in the " 0 " state, and the $l$ th unit works in the PWM state.

(3) When $\left(\mathrm{V}_{\mathrm{r}} \leq 0\right.$ and $\left.\mathrm{I}_{\mathrm{S}}>0\right),(l-1)$ units with lower voltage errors are charging in the " -1 " state, $(m-l)$ units with higher voltage errors operate in the " 0 " state, and the lth unit works in the PWM state.

(4) When $\left(\mathrm{V}_{\mathrm{r}} \leq 0\right.$ and $\left.\mathrm{I}_{\mathrm{S}} \leq 0\right),(l-1)$ units with higher voltage errors are discharging in the " -1 " state, $(m-l)$ units with lower voltage errors operate in the " 0 " state, and the lth unit works in the PWM state.

\subsection{Fault Mode}

(1) When $\left(\mathrm{V}_{\mathrm{r}}>0\right.$ and $\left.\mathrm{I}_{\mathrm{S}}>0\right)$, and the value of $(m-l)$ is even, $(m-l) / 2$ units with lower voltage errors are charging in the " -1 " state, the $((m-l+2) / 2)$ th unit works in the PWM state, and the remaining units operate in the " +1 " state.

(2) When $\left(\mathrm{V}_{\mathrm{r}}>0\right.$ and $\left.\mathrm{I}_{\mathrm{S}}>0\right)$, and the value of $(m-l)$ is uneven, $(m-l-1) / 2$ units with lower voltage errors are charging in the " -1 " state, the $((m-l+1) / 2)$ th unit works in the PWM state, and the remaining units operate in the " +1 " state.

(3) When $\left(\mathrm{V}_{\mathrm{r}}>0\right.$ and $\left.\mathrm{I}_{\mathrm{S}} \leq 0\right)$, and the value of $(m-l)$ is even, $(m+l-2) / 2$ units with lower voltage errors are charging in the " +1 " state, the $((m+l) / 2)$ th unit works in the PWM state, and the remaining units operate in the " -1 " state.

(4) When $\left(\mathrm{V}_{\mathrm{r}}>0\right.$ and $\left.\mathrm{I}_{\mathrm{S}} \leq 0\right)$, and the value of $(m-l)$ is uneven, $(m+l-1) / 2$ units with lower voltage errors are charging in the " +1 " state, the $((m+l+1) / 2)$ th unit works in the PWM state, and the remaining units operate in the " -1 " state.

(5) When $\left(\mathrm{V}_{\mathrm{r}} \leq 0\right.$ and $\left.\mathrm{I}_{\mathrm{S}}>0\right)$, and the value of $(m-l)$ is even, $(m+l-2) / 2$ units with lower voltage errors are charging in the " -1 " state, the $((m+l) / 2)$ th unit works in the PWM state, and the remaining units operate in the " +1 " state.

(6) When $\left(\mathrm{V}_{\mathrm{r}} \leq 0\right.$ and $\left.\mathrm{I}_{\mathrm{S}}>0\right)$, and the value of $(m-l)$ is uneven, $(m+l-1) / 2$ units with lower voltage errors are charging in the " -1 " state, the $((m+l+1) / 2)$ th unit works in the PWM state, and the remaining units operate in the " +1 " state.

(7) When $\left(\mathrm{V}_{\mathrm{r}} \leq 0\right.$ and $\left.\mathrm{I}_{\mathrm{S}} \leq 0\right)$, and the value of $(m-l)$ is even, $(m-l) / 2$ units with lower voltage errors are charging in the " +1 " state, the $((m-l+2) / 2)$ th unit works in the PWM state, and the remaining units operate in the the " -1 " state.

(8) When $\left(\mathrm{V}_{\mathrm{r}} \leq 0\right.$ and $\left.\mathrm{I}_{\mathrm{S}} \leq 0\right)$, and the value of $(m-l)$ is uneven, $(m-l-1) / 2$ units with lower voltage errors are charging in the " +1 " state, the $((m-l+1) / 2)$ th unit works in the PWM state, and the remaining units operate in the " -1 " state.

\section{Simulation Verification}

To verify the performance of the proposed method, an CHB inverter which consists of five modules is simulated in MATLAB/Simulink. The PV panel is a JAP6-60-255/4BB and the specifications and equivalent circuit parameters are given in Table 2. Table 3 shows the inverter and grid parameters.

Table 2. Parameters of the PV panel.

\begin{tabular}{ccc}
\hline Symbol & Parameter & Value \\
\hline $\mathrm{P}_{\mathrm{m}}$ & Max power & $255 \mathrm{~W}$ \\
$\mathrm{~V}_{\mathrm{oc}}$ & Open circuit voltage & $37.61 \mathrm{~V}$ \\
$\mathrm{~V}_{\mathrm{mp}}$ & Max power voltage & $30.59 \mathrm{~V}$ \\
$\mathrm{I}_{\mathrm{sc}}$ & Short circuit current & $8.90 \mathrm{~A}$ \\
$\mathrm{I}_{\mathrm{mp}}$ & Max power current & $8.34 \mathrm{~A}$ \\
\hline
\end{tabular}


Table 3. Parameters of power grid and inverter.

\begin{tabular}{ccc}
\hline Symbol & Parameter & Value \\
\hline $\mathrm{C}_{i}$ & DC-side capacitor & $14.1 \mathrm{mF}$ \\
$\mathrm{L}_{\mathrm{s}}$ & Filter inductance & $1.8 \mathrm{mH}$ \\
$\mathrm{V}_{\mathrm{m}}$ & Peak value of grid voltage & $130 \mathrm{~V}$ \\
$f_{\text {grid }}$ & Frequency of grid voltage & $50 \mathrm{~Hz}$ \\
$f_{\mathrm{c}}$ & PWM frequency & $2500 \mathrm{~Hz}$ \\
$f_{\text {sort }}$ & Frequency of mode change & $500 \mathrm{~Hz}$ \\
\hline
\end{tabular}

\subsection{Normal Mode}

In order to investigate the performance of both HMSWZS and SHMS in terms of DC-side voltage fluctuation and average output power of the PV module under identical conditions, the DC-side voltage $\left(\mathrm{V}_{\mathrm{PV} 1}\right)$ and output power $\left(\mathrm{P}_{1}\right)$ of the PV module in the first $\mathrm{H}$-bridge are shown in Figure 8 . The simulation starts with the operation of the system under symmetrical condition $\left(\mathrm{E}=1000 \mathrm{~W} / \mathrm{m}^{2}\right.$ and $\mathrm{T}=25^{\circ} \mathrm{C}$ ). In the simulation, since the focus of this paper is to study the influence of DC-side voltage fluctuation on the energy acquisition of PV module, the reference of the DC-side voltage is set directly at the maximum power point of PV module instead of adopting the MPPT algorithm. As shown in Figure 8, the maximum fluctuation of $\mathrm{V}_{\mathrm{PV} 1}$ is $4.95 \mathrm{~V}$ when HMSWZS is utilized, while that of SHMS is only $3.40 \mathrm{~V}$, which is reduced by up to $31.30 \%$. With the HMSWZS, the output power of the first PV module ranges from $220-255.1 \mathrm{~W}$, and the average is about $251.9 \mathrm{~W}$. Since the SHMS is utilized to reduce the DC-side voltage fluctuation, the output power ranges from 245-255.1 W and the average is about $253.4 \mathrm{~W}$. Figure 9 shows the total output power $\left(\mathrm{P}_{\mathrm{T}}\right)$ of the $\mathrm{CHB}$ inverter with both methods. As shown in Figure 9, with HMSWZS, the total output power of the CHB inverter ranges from $1243-1275 \mathrm{~W}$ and the average is about $1262 \mathrm{~W}$. When SHMS is utilized, the total output power of the $\mathrm{CHB}$ inverter ranges from $1256-1277 \mathrm{~W}$ and the average is about $1269.2 \mathrm{~W}$. Compared with the HMSWZS, the efficiency of the CHB inverter can be improved about $0.56 \%$ by adopting the SHMS. Therefore, under the normal mode, the SHMS has a superior capacity of suppressing the DC-side voltage fluctuation compared with the HMSWZS, thereby improving the energy collection of the PV module.

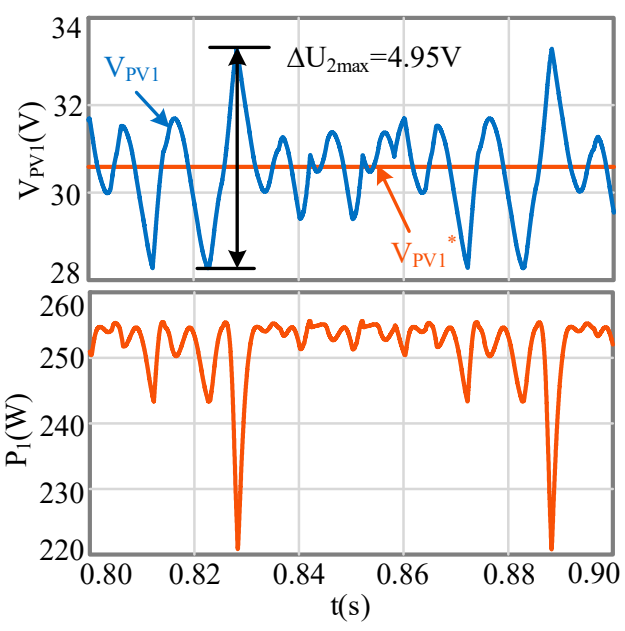

(a)

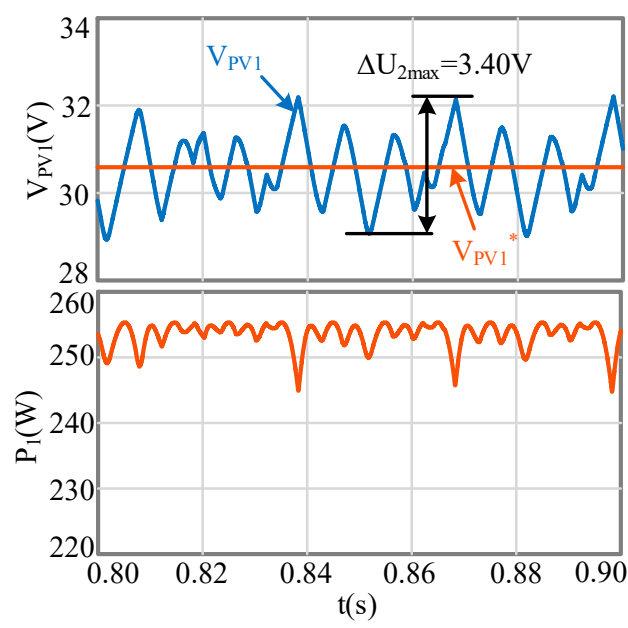

(b)

Figure 8. Simulation results under normal mode: the DC-side voltage $\left(\mathrm{V}_{\mathrm{PV} 1}\right)$, and output power $\left(\mathrm{P}_{1}\right)$ of the PV module in the first H-bridge with: (a) HMSWZS and (b) SHMS. 


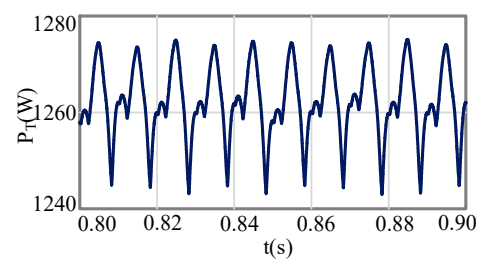

(a)

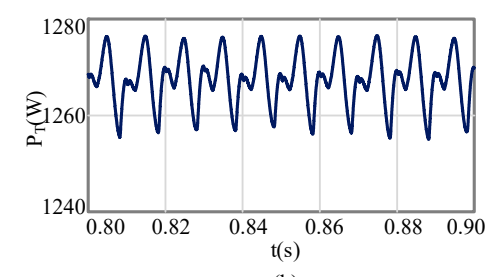

(b)

Figure 9. Simulation results of the total output power of the CHB inverter under the normal mode with: (a) HMSWZS and (b) SHMS.

\subsection{Fault Mode}

The following simulation evaluates the performance of HMSCZS and SHMS under the fault mode where the second PV module fails. The simulation starts with the operation of the system under symmetrical condition $\left(\mathrm{E}=1000 \mathrm{~W} / \mathrm{m}^{2}\right.$ and $\left.\mathrm{T}=25^{\circ} \mathrm{C}\right)$. At $\mathrm{t}=1.5 \mathrm{~s}$, the second $\mathrm{PV}$ module is removed owing to the fault and, thus, the $\mathrm{CHB}$ inverter is operating in the fault condition. Figure 10 depicts the total modulation voltage $\left(\mathrm{V}_{\mathrm{r}}\right)$ and $\mathrm{DC}$-side capacitor current of the second H-bridge $\left(\mathrm{I}_{\mathrm{C} 2}\right)$ with both methods. As shown in Figure 10a $I_{C 2}$ is always negative regardless of the polarity of $V_{r}$ and, thus, $\mathrm{V}_{\mathrm{PV} 2}$ gradually diverges from the reference value. As a result, all the $\mathrm{DC}$-side voltages diverge from the references in steady state, which is visible in Figure 11a. For comparison, the SHMS is also subjected to the same test under the identical condition. As presented in Figure $10 \mathrm{~b}, \mathrm{I}_{\mathrm{C} 2}$ can be positive and negative whether $\mathrm{V}_{\mathrm{r}}$ is positive or negative and, thus, the DC-side capacitor of the second $\mathrm{H}$-bridge could realize the equalization of the charge-discharge. Therefore, the CHB inverter is able to operate properly under fault condition, which is obvious in Figure 11b. Figure 12 shows the output power of the PV module in all H-bridges with both methods. As shown in Figure 12, due to the removal of the second PV module, the output power of the second H-bridge is, therefore, zero. The output power of the PV module in other H-bridges ranges from 243.2-255.1 W by using SHMS and the average is about $253.2 \mathrm{~W}$. However, due to the deviation of the DC-side voltage, the output power of the PV module in other H-bridges ranges from 221.4-255.1 W by utilizing HMSCZS and the average is only about $245.3 \mathrm{~W}$. The total output power $\left(\mathrm{P}_{\mathrm{T}}\right)$ of the $\mathrm{CHB}$ inverter with both methods are shown in Figure 13. As could be seen from Figure 13, with HMSCZS, the total output power of the CHB inverter ranges from 935.9-1016 W and the average is about 982.2 W. When SHMS is utilized, the total output power of the $\mathrm{CHB}$ inverter ranges from 1000-1020 $\mathrm{W}$ and the average is about $1014 \mathrm{~W}$. Compared with the HMSCZS, the efficiency of the CHB inverter can be improved about $3.12 \%$ by adopting the SHMS. Therefore, under the fault mode, the SHMS is still able to make the DC-side voltages reach the references, thus maintaining a higher energy yield.

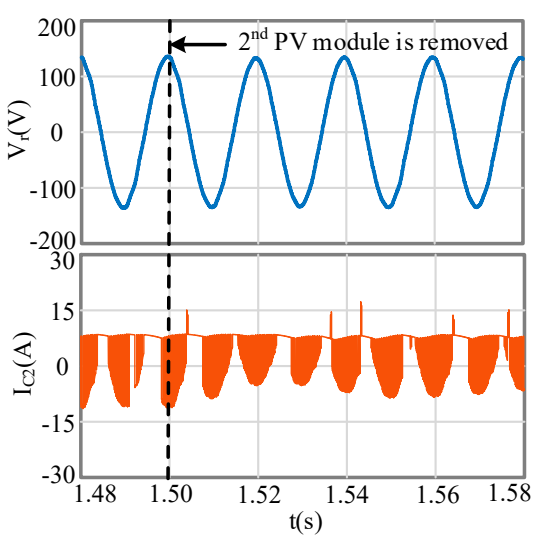

(a)

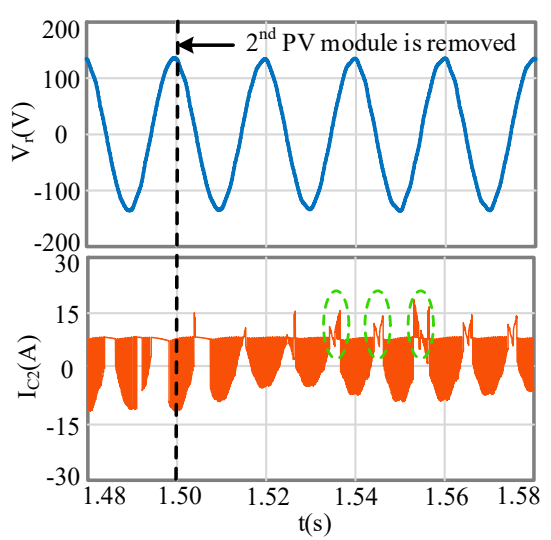

(b)

Figure 10. Simulation results under fault mode: the total modulation voltage $\left(\mathrm{V}_{\mathrm{r}}\right)$, and DC-side capacitor current of the second H-bridge $\left(\mathrm{I}_{\mathrm{C} 2}\right)$ with: (a) HMSCZS and (b) SHMS. 

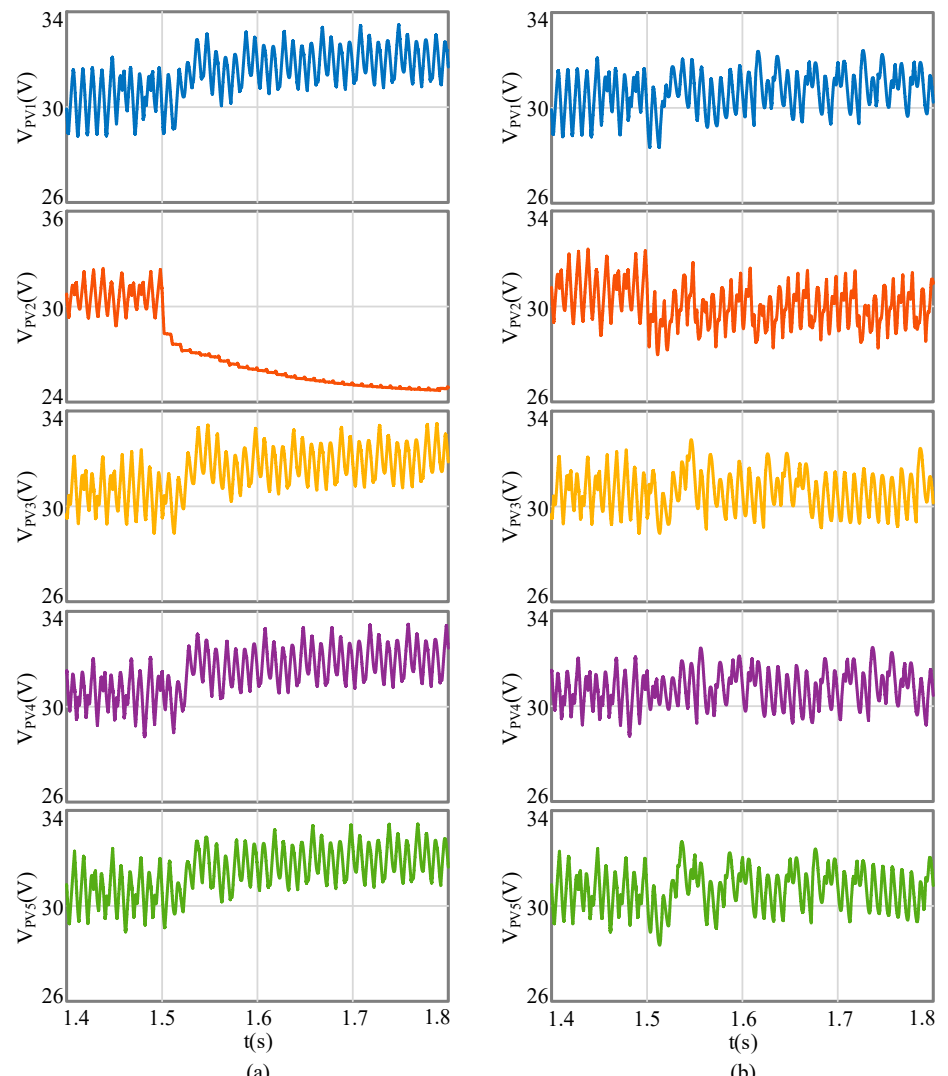

Figure 11. Simulation results under fault mode: DC-side voltages of all H-bridges with: (a) HMSCZS, and (b) SHMS.
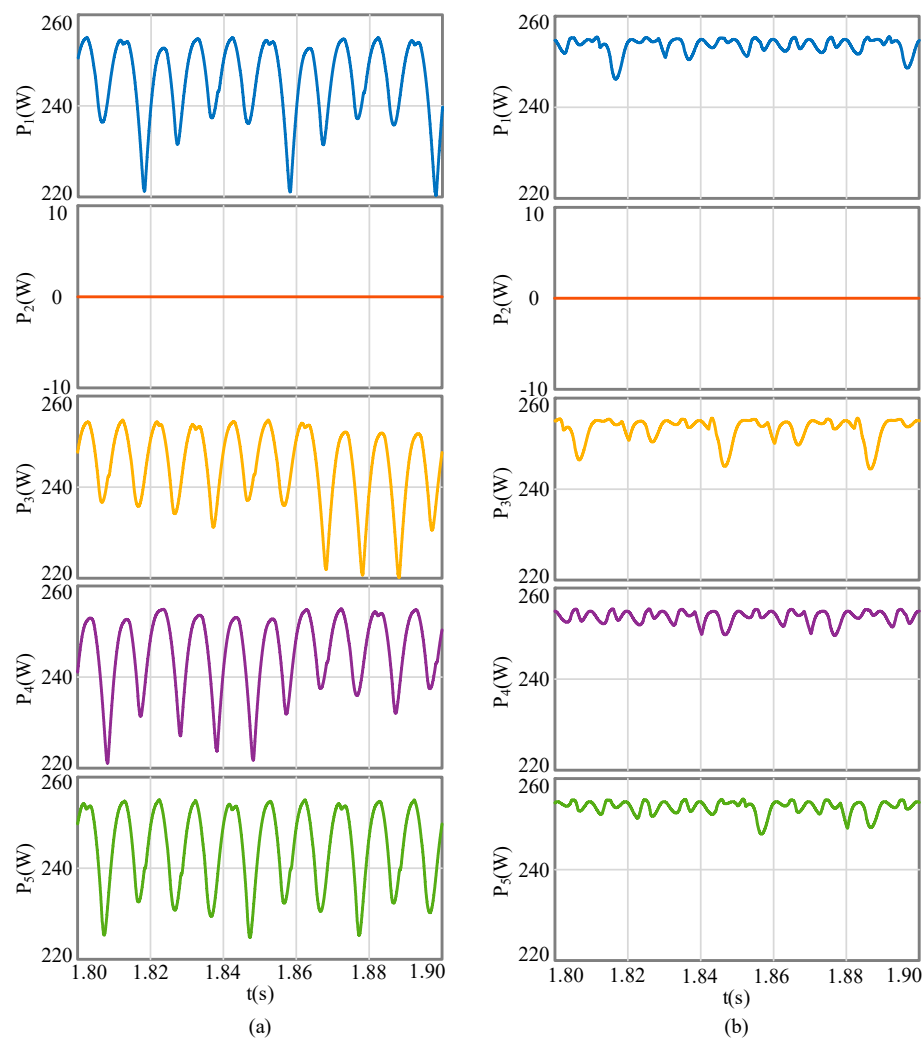

Figure 12. Simulation results under fault mode: the output power of PV module in all H-bridges with: (a) HMSCZS and (b) SHMS. 


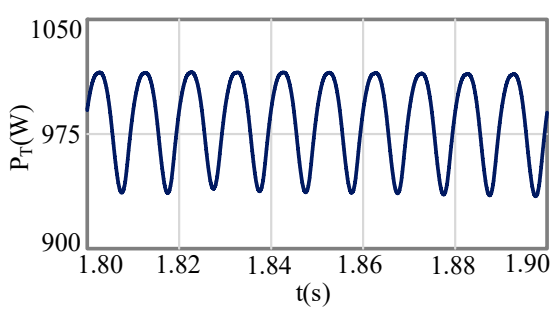

(a)

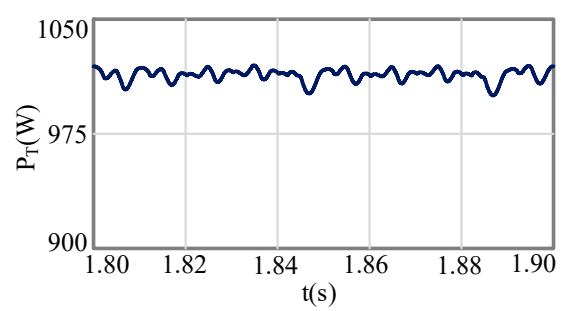

(b)

Figure 13. Simulation results of the total output power of the $\mathrm{CHB}$ inverter under the fault mode with: (a) HMSCZS and (b) SHMS.

\section{Experimental Results}

As shown in Figure 14, an experimental prototype with five H-bridge units has been established to validate the effectiveness of the proposed strategy. The prototype includes a central controller and five local controllers. The BECKHOFF industrial PC (CX2040) is utilized as the central controller and TMS320F28335 processors are used as local controllers which communicate with each other through an EtherCAT real-time communication network. The EtherCAT protocol features not only enhance the effective synchronization between master and slave clocks, but also improves the synchronization between the H-bridge units. Since the testing equipment of the university laboratory is limited, only the first H-bridge unit is connected to a Chroma62020H-150S PV simulator, and the DC side of the four other H-bridge units are connected to a $36 \mathrm{~V}$ switching power supply through a $0.5 \Omega$ resistance, respectively, to simulate PV modules. Given that there are only five H-bridge units in the experiment, the output of the inverter is connected to the $130 \mathrm{~V}$ AC grid regulated by a voltage regulator. The other parameters of the experimental system are the same as the simulation parameters.

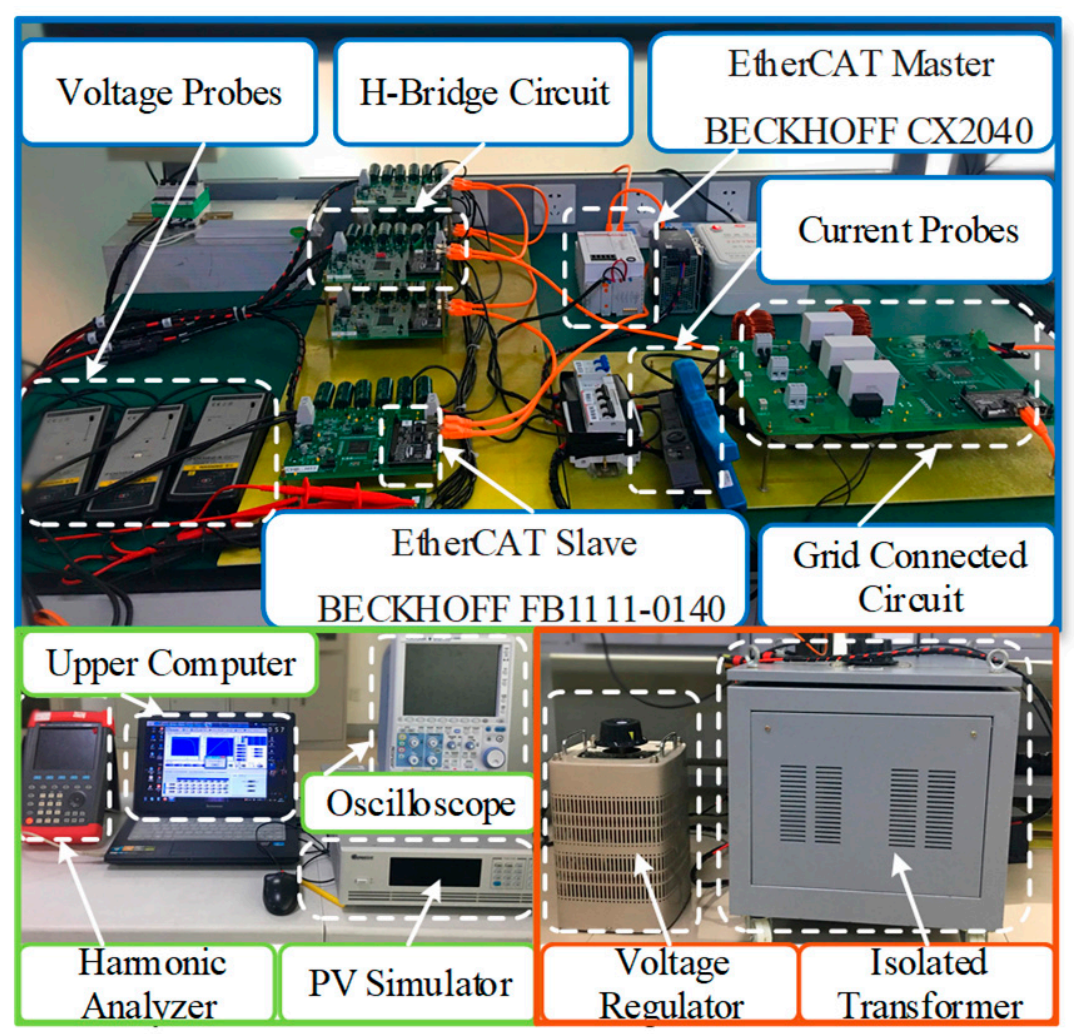

Figure 14. Experimental platform of the single-phase PV CHB module level inverter. 


\subsection{Normal Mode}

The first experiment has been carried out under the initial conditions of PV simulator with irradiance of $1000 \mathrm{~W} / \mathrm{m}^{2}$ and a temperature of $25^{\circ} \mathrm{C}$. In this case, the input power of the first H-bridge unit is approximately $255 \mathrm{~W}$. The reference of the other four H-bridge units' DC-side voltages is 32.02 $\mathrm{V}$, and therefore the output power of the other four H-bridges is about $255 \mathrm{~W}$ in theory. As depicted in the Figure 15, both SHMS and HMSWZS enable the CHB inverter to operate at unity power factor with good grid current quality. It can also be seen that SHMS contains four output modes: "+1", " -1 ", PWM, and "0" mode, which is never adopted in HMSWZS.

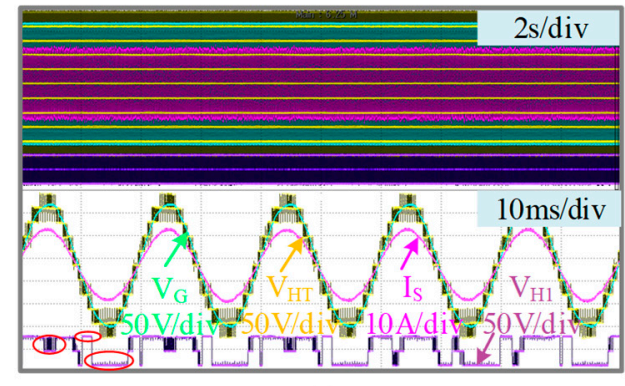

(a)

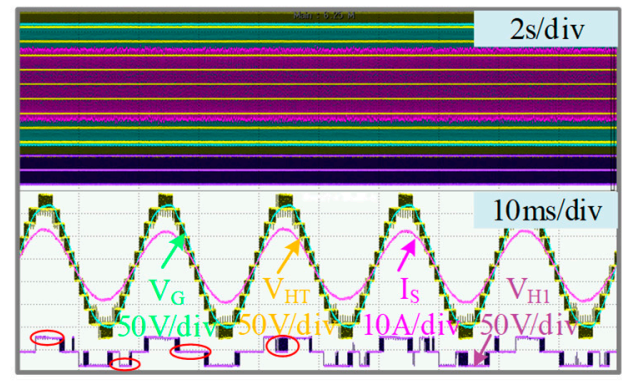

(b)

Figure 15. Experimental results under normal mode: grid voltage $\left(V_{G}\right)$, grid current $\left(I_{S}\right)$ and the total output voltage of $\mathrm{CHB}$ inverter $\left(\mathrm{V}_{\mathrm{HT}}\right)$; the first $\mathrm{H}$-bridge output voltage $\left(\mathrm{V}_{\mathrm{H} 1}\right)$ with: (a) HMSWZS and (b) SHMS.

For the sake of evaluating the characteristic of both two modulation methods in terms of DC-side voltage fluctuation and average output power of the PV module, the following experiments have been performed under the same conditions as the first experiment. As shown in Figure 16, the maximum fluctuation of $\mathrm{V}_{\mathrm{PV} 1}$ by adopting HMSWZS is $5.3 \mathrm{~V}$, but the value is only $4.1 \mathrm{~V}$ for SHMS, which is reduced by about $22.64 \%$. In order to compare the output power of the two methods under normal mode, the total output power of the CHB inverter is recorded by the upper computer, respectively. As can be seen from Figure 17, with HMSWZS, the total output power of the CHB inverter ranges from 1218-1244.2 W and the average is about $1233.7 \mathrm{~W}$. When SHMS is utilized, the total output power of the CHB inverter ranges from 1230-1249.3 W and the average is about $1239.8 \mathrm{~W}$. Compared with the HMSWZS, the efficiency of the CHB inverter can be improved about $0.48 \%$ by adopting the SHMS. Furthermore, the efficiency of the CHB inverter with both methods is presented in Figure 18. As can be seen from Figure 18, the SHMS is capable of improving the efficiency of the CHB inverter compared with the HMSWZS. Therefore, under normal mode, the SHMS is able to effectively suppress the DC-side voltage fluctuation compared with the HMSWZS, thereby improving the energy acquisition of the PV module.

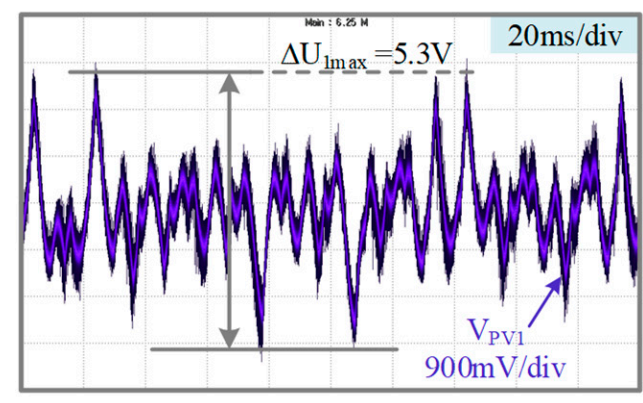

(a)

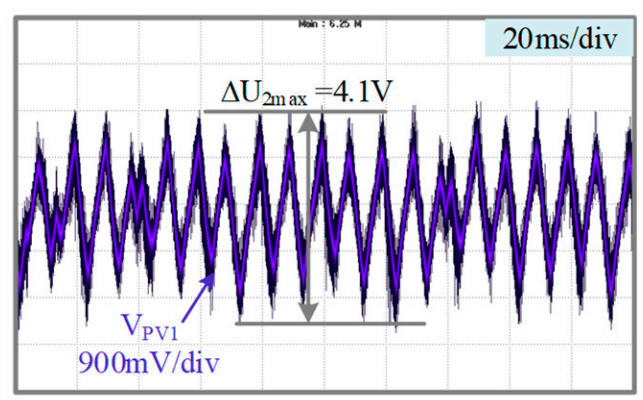

(b)

Figure 16. Experimental results under normal mode: the DC-side voltage $\left(\mathrm{V}_{\mathrm{PV} 1}\right)$ of the first H-bridge with: (a) HMSWZS, and (b) SHMS. 


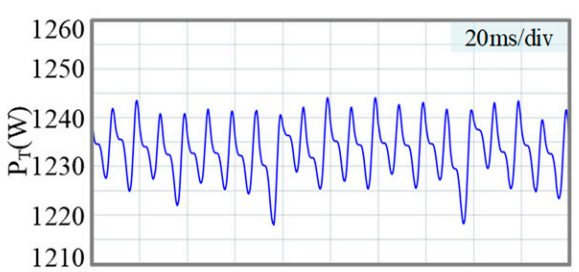

(a)

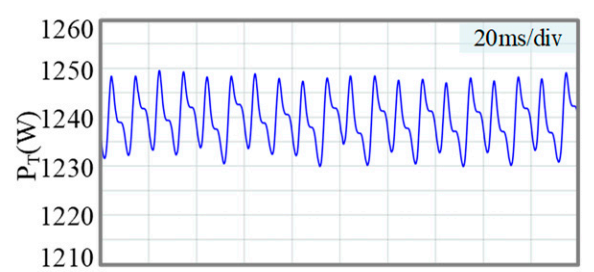

(b)

Figure 17. Experimental results of the total output power of the $\mathrm{CHB}$ inverter under normal mode with: (a) HMSWZS and (b) SHMS.

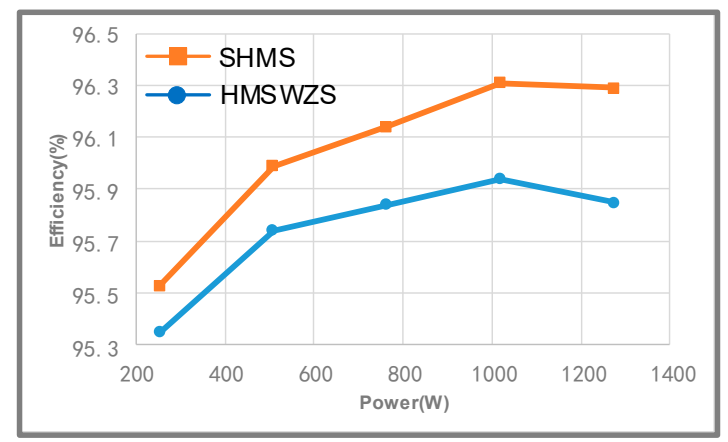

Figure 18. Experimental results of the efficiency of the $\mathrm{CHB}$ inverter under normal mode with different methods.

\subsection{Fault Mode}

The last experiment is conducted to evaluate the performance of SHMS and HMSCZS in the fault mode where the PV module fails. Initially, the CHB inverter and PV modules are operating in normal mode as indicated in the first experiment. Then the second PV module is removed. As can be seen from Figure 19a,b, both the HMSCZS and SHMS can keep the CHB inverter stable and operating at a unity power factor without interruption. As is presented in the Figure 19a, by using the HMSCZS, the fault $\mathrm{H}$-bridge unit can operate only in " 0 " or " $+\mathrm{PWM}$ " mode when $\mathrm{V}_{\mathrm{G}}$ is positive and " 0 " or "-PWM" mode when $\mathrm{V}_{\mathrm{G}}$ is negative. In such condition, the fault $\mathrm{H}$-bridge unit is always in discharge status and unable to realize the equalization of the charge-discharge. Consequently, as presented in Figure 19c, the DC-side voltages of all H-bridge units diverge from the references in the steady state, which may result in low generated power of the CHB inverter. However, as presented in the Figure 19b, by utilizing the SHMS, the fault H-bridge unit can operate in " +1 ", "+PWM", " -1 " or "-PWM" mode whether the grid voltage $\left(\mathrm{V}_{\mathrm{G}}\right)$ is positive or negative. Therefore, as depicted in the Figure 19d, the SHMS is capable of realizing the equalization of the charge-discharge of the fault $\mathrm{H}$-bridge unit and maintaining the DC-side voltage balance of the other $\mathrm{H}$-bridge units. In order to compare the output power of the two methods under fault mode, the total output power of the CHB inverter is recorded by the upper computer respectively. As can be seen from Figure 20, with HMSCZS, the total output power of the CHB inverter ranges from 919.2-986.4 W and the average is about $948.8 \mathrm{~W}$. When SHMS is utilized, the total output power of the CHB inverter ranges from 972.3-988.6 W and the average is about $978.2 \mathrm{~W}$. Compared with the HMSCZS, the efficiency of the CHB inverter can be improved about $2.89 \%$ by adopting the SHMS. Furthermore, the efficiency of the CHB inverter with both methods is presented in Figure 21. As can be seen from Figure 21, the SHMS is capable of improving the efficiency of the CHB inverter compared with the HMSCZS. Therefore, under the fault mode, the SHMS is able to make the DC-side voltages reach the references, thus maintaining a higher energy yield. 


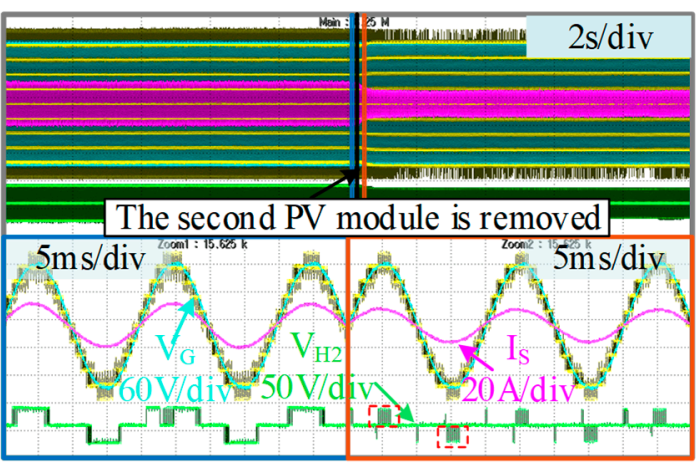

(a)

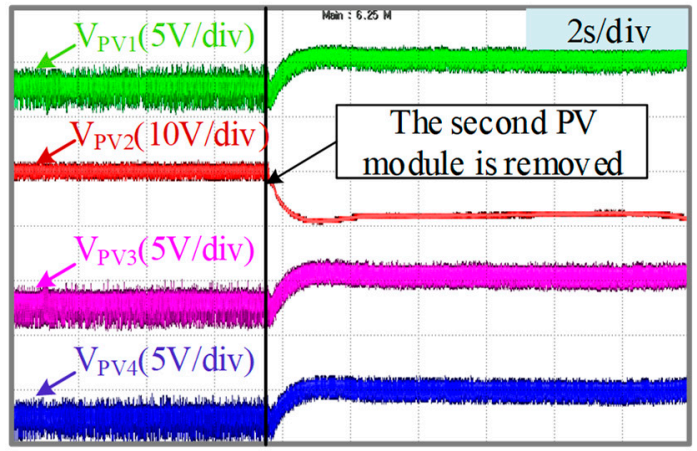

(c)

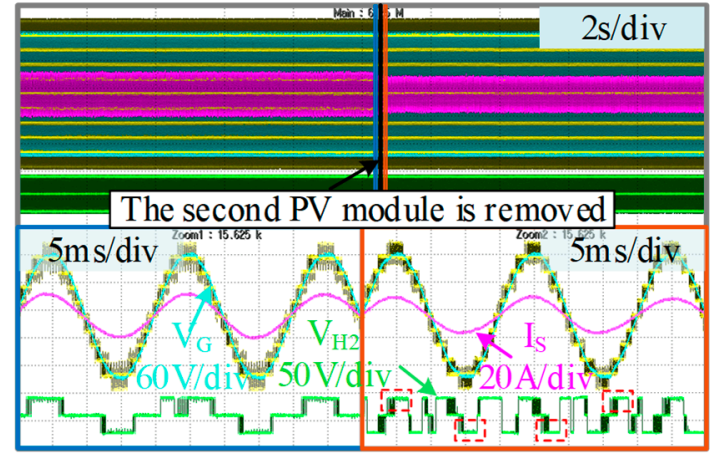

(b)

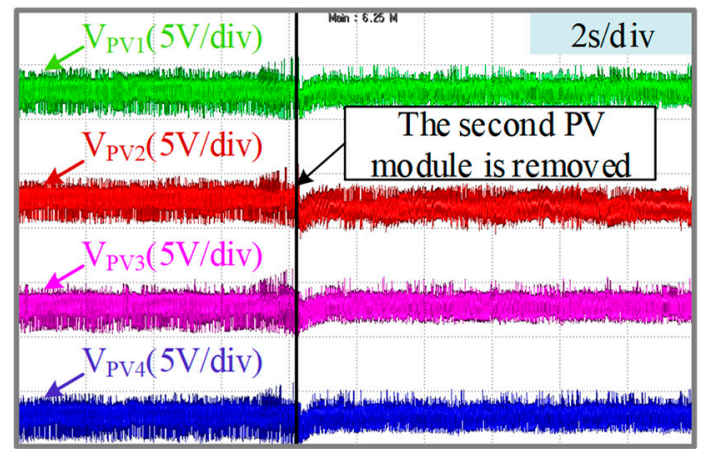

(d)

Figure 19. Experimental results under fault mode: grid voltage $\left(V_{G}\right)$, grid current $\left(I_{S}\right)$, and the second H-bridge output voltage $\left(\mathrm{V}_{\mathrm{H} 2}\right)$ with: (a) HMSCZS and (b) SHMS; DC-side voltages of all H-bridge units with: (c) HMSCZS and (d) SHMS.

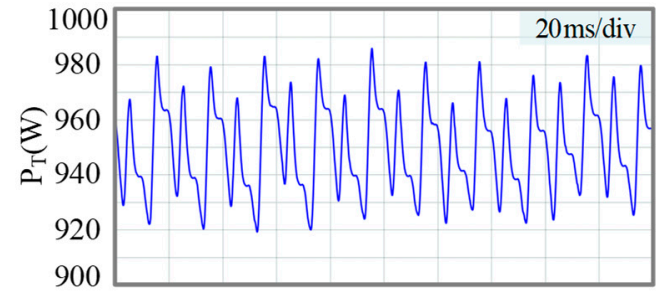

(a)

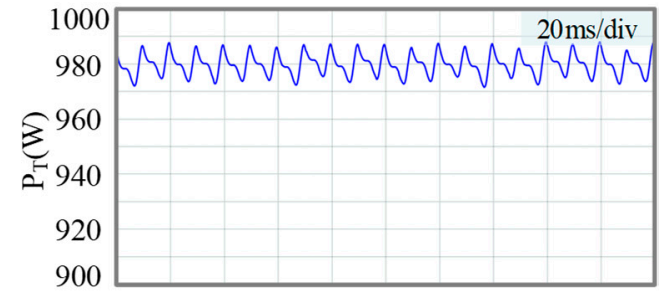

(b)

Figure 20. Experimental results of the total output power of the $\mathrm{CHB}$ inverter under fault mode with: (a) HMSCZS and (b) SHMS.

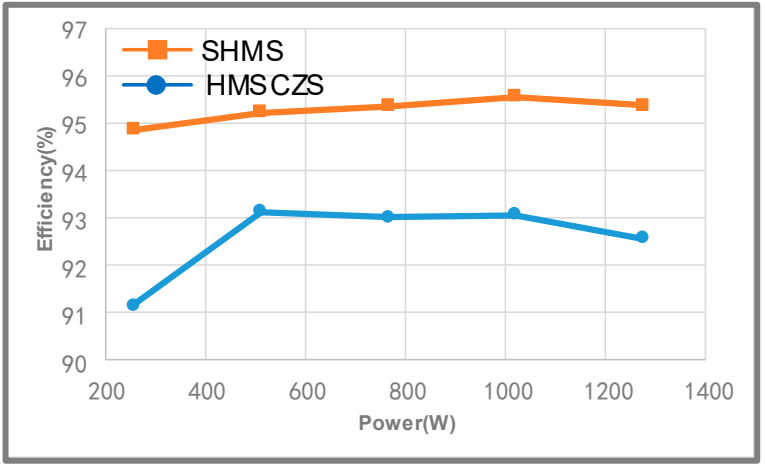

Figure 21. Experimental results of the efficiency of the $\mathrm{CHB}$ inverter under the fault mode with different methods. 


\section{Conclusions}

This paper proposes a switching hybrid modulation strategy, which can effectively reduce the fluctuation of DC-side voltage and maximize the output power of a PV CHB grid-connected inverter. When the CHB inverter is operating in the normal mode, the hybrid modulation strategy containing the zero state is adopted to suppress DC-side voltage fluctuation, thereby improving the output power of PV modules. Once the CHB inverter is operating in the fault mode, owing to failing solar panels, the hybrid modulation strategy without the zero state is utilized to make the DC-side voltages reach the references, thus, maintaining a higher energy yield under the fault condition. A set of experimental results demonstrate that, with this method, the output energy of the PV modules is improved both in the normal mode and fault mode.

Author Contributions: Conceptualization: X.Z. and W.M.; data curation: Y.H.; formal analysis: W.M. and T.Z.; funding acquisition: F.W. and F.L.; methodology: X.Z.; resources: X.Z. and R.C.; software: Y.H.; validation: W.M.; writing-original draft: W.M.; writing—review and editing: W.M.

Funding: This work was funded by the National Key Research and Development Program of China (No. 2018YFB1500703) and the National Natural Science Foundation of China (No. 51677049).

Conflicts of Interest: The authors declare no conflict of interest.

\section{References}

1. Schweizer, M.; Friedli, T.; Kolar, J.W. Comparative evaluation of advanced three-phase three-level inverter/converter topologies against two-level systems. IEEE Trans. Ind. Electron. 2012, 60, 5515-5527. [CrossRef]

2. Villanueva, E.; Correa, P.; Rodríguez, J.; Pacas, M. Control of a single-phase cascaded H-bridge multilevel inverter for grid-connected photovoltaic systems. IEEE Trans. Ind. Electron. 2009, 56, 4399-4406. [CrossRef]

3. Xiao, B.; Hang, L.; Mei, J.; Riley, C.; Tolbert, L.M.; Ozpineci, B. Modular cascaded H-bridge multilevel PV inverter with distributed MPPT for grid-connected applications. In Proceedings of the IEEE International Conference on Robotics and Automation, New Orleans, LA, USA, 26 April-1 May 2004; pp. 1722-1731.

4. Mercorelli, P.; Kubasiak, N.; Liu, S. Multilevel bridge governor by using model predictive control in wavelet packets for tracking trajectories. In Proceedings of the IEEE International Conference on Robotics and Automation (ICRA), New Orleans, LA, USA, 26 April-1 May 2004; 2004; Volume 4, pp. 4079-4084.

5. Townsend, C.D.; Yu, Y.; Konstantinou, G.; Agelidis, V.G. Cascaded H-bridge multilevel PV topology for alleviation of per-phase power imbalances and reduction of second harmonic voltage ripple. IEEE Trans. Power Electron. 2016, 31, 5574-5586. [CrossRef]

6. Rivera, S.; Kouro, S.; Wu, B.; Leon, J.I.; Rodríguez, J.; Franquelo, L.G. Cascaded H-bridge multilevel converter multistring topology for large scale photovoltaic systems. In Proceedings of the IEEE International Symposium on Industrial Electronics, Gdansk, Poland, 27-30 June 2011; pp. 1837-1844.

7. Sun, D.; Ge, B.; Yan, X.; Bi, D.; Zhang, H.; Liu, Y.; Peng, F.Z. Modeling, impedance design, and efficiency analysis of quasi-Z source module in cascaded multilevel photovoltaic power system. IEEE Trans. Ind. Electron. 2014, 61, 6108-6117. [CrossRef]

8. Mercorelli, P.; Kubasiak, N.; Liu, S. Model predictive control of an electromagnetic actuator fed by multilevel PWM inverter. In Proceedings of the 2004 IEEE International Symposium on Industrial Electronics, Ajaccio, France, 4-7 May 2004; Volume 1, pp. 531-535.

9. Mercorelli, P. A Multilevel inverter bridge control structure with energy storage using model predictive control for flat systems. J. Eng. 2013, 2013, 750190. [CrossRef]

10. Yu, Y.; Konstantinou, G.; Hredzak, B.; Agelidis, V.G. Power balance of cascaded H-bridge multilevel converters for large-scale photovoltaic integration. IEEE Trans. Power Electron. 2016, 31, 292-303. [CrossRef]

11. Vazquez, S.; Leon, J.I.; Carrasco, J.M.; Franquelo, L.G.; Galvan, E.; Reyes, M.; Dominguez, E. Analysis of the power balance in the cells of a multilevel cascaded H-bridge converter. IEEE Trans. Ind. Electron. 2010, 57, 2287-2296. [CrossRef]

12. Rezaei, M.A.; Farhangi, S.; Iman-Eini, H. Extending the operating range of cascaded H-bridge based multilevel rectifier under unbalanced load conditions. In Proceedings of the 2010 IEEE International Conference on Power and Energy, Kuala Lumpur, Malaysia, 29 November-1 December 2010; pp. 780-785. 
13. Wang, S.; Zhao, J.; Yao, X.; Sun, Y. Power balanced controlling of cascaded inverter for grid-connected photovoltaic systems under unequal irradiance conditions. Trans. Chin. Electrotech. Soc. 2012, 28, 251-261.

14. Kouro, S.; Wu, B.; Moya, Á.; Villanueva, E.; Correa, P.; Rodríguez, J. Control of a cascaded H-bridge multilevel converter for grid connection of photovoltaic systems. In Proceedings of the 2009 35th Annual Conference of IEEE Industrial Electronics, Porto, Portugal, 3-5 November 2009; pp. 3976-3982.

15. Rivera, S.; Wu, B.; Lizana, R.; Kouro, S.; Perez, M.; Rodriguez, J. Modular multilevel converter for large-scale multistring photovoltaic energy conversion system. In Proceedings of the 2013 IEEE Energy Conversion Congress and Exposition, Denver, CO, USA, 15-19 September 2013; pp. 1941-1946.

16. Rezaei, M.A.; Iman-Eini, H.; Farhangi, S. Grid-connected photovoltaic system based on a cascaded h-bridge inverter. J. Power Electron. 2012, 12, 578-586. [CrossRef]

17. Liu, L.; Li, H.; Xue, Y.; Liu, W. Reactive power compensation and optimization strategy for grid-interactive cascaded photovoltaic systems. IEEE Trans. Power Electron. 2015, 30, 188-202. [CrossRef]

18. Eskandari, A.; Javadian, V.; Iman-Eini, H.; Yadollahi, M. Stable operation of grid connected cascaded H-bridge inverter under unbalanced insolation conditions. In Proceedings of the 2013 3rd International Conference on Electric Power and Energy Conversion Systems, Istanbul, Turkey, 2-4 October 2013; pp. 1-6.

19. Iman-Eini, H.; Schanen, J.L.; Farhangi, S.; Roudet, J. A modular strategy for control and voltage balancing of cascaded H-bridge rectifiers. IEEE Trans. Power Electron. 2008, 23, 2428-2442. [CrossRef]

20. Keshavarzian, A.; Iman-Eini, H. A redundancy-based scheme for balancing DC-link voltages in cascaded H-bridge rectifiers. IET Power Electron. 2013, 6, 235-243. [CrossRef]

21. Moosavi, M.; Farivar, G.; Iman-Eini, H.; Shekarabi, S.M. A voltage balancing strategy with extended operating region for cascaded H-bridge converters. IEEE Trans Power Electron. 2014, 29, 5044-5053. [CrossRef]

22. Coppola, M.; Di Napoli, F.; Guerriero, P.; Iannuzzi, D.; Daliento, S.; Del Pizzo, A. An FPGA-based advanced control strategy of a grid-tied PV CHB inverter. IEEE Trans. Power Electron. 2016, 31, 806-816. [CrossRef]

23. Zhao, T.; Zhang, X.; Mao, W.; Wang, F.; Xu, J.; Gu, Y. A modified hybrid modulation strategy for suppressing DC voltage fluctuation of cascaded H-bridge photovoltaic inverter. IEEE Trans. Ind. Electron. 2018, 65, 3932-3941. [CrossRef]

24. Miranbeigi, M.; Iman-Eini, H. Hybrid modulation technique for grid-connected cascaded photovoltaic systems. IEEE Trans. Ind. Electron. 2016, 63, 7843-7853. [CrossRef]

25. Zmood, D.N.; Holmes, D.G. Stationary frame current regulation of PWM inverters with zero steady-state error. IEEE Trans. Power Electron. 2003, 18, 814-822. [CrossRef]

26. Kim, S.Y.; Park, S.Y. Compensation of dead-time effects based on adaptive harmonic filtering in the vector-controlled AC motor drives. IEEE Trans. Ind. Electron. 2007, 54, 1768-1777. [CrossRef]

27. Zhu, D.; Zou, X.; Deng, L.; Huang, Q.; Zhou, S.; Kang, Y. Inductance-emulating control for DFIG-based wind turbine to ride-through grid faults. IEEE Trans. Power Electron. 2017, 32, 8514-8525. [CrossRef] 